(2) Open Access Full Text Article

\title{
Gamma linolenic acid regulates PHD2 mediated hypoxia and mitochondrial apoptosis in DEN induced hepatocellular carcinoma
}

This article was published in the following Dove Press journal:

Drug Design, Development and Therapy

\author{
Hong Cui' \\ Feng Han' \\ Ling Zhang' \\ Li Wang' \\ Mukesh Kumar ${ }^{2}$ \\ 'Department of Hepatobiliary and \\ Pancreatic Surgery, The Affiliated \\ Tumor Hospital of Zhengzhou \\ University, Zhengzhou City, Henan \\ Province 450008 , China; ${ }^{2}$ Chandra \\ Shekhar Singh College of Pharmacy, \\ Allahabad, India
}

\begin{abstract}
Introduction: Hepatocellular carcinoma (HCC) is one of the known major health problems across the globe, and is sixth ranked among all cancer, due to its high mortality rate. Polyunsaturated fatty acids (PUFAs) play an important role in the formation of a cell membrane, along with the fluidity of the membrane and proteins. Gamma linolenic acid (GLA) is member of the $\omega-6$ family of PUFAs and converts into the arachidonic acid via a series of elongation and desaturation reactions. The aim of the current investigation was to scrutinize the effect of GLA on mitochondrial mediated apoptosis and anti-inflammatory pathway against diethylnitrosamine (DEN) induced HCC.
\end{abstract}

Materials and methods: Chemical carcinogenesis in Wistar rats was introduced by an intraperitoneal dose of DEN ( $200 \mathrm{mg} / \mathrm{kg})$. The rats received the various doses of GLA for 22 weeks. The progressions of serum biomarkers and histopathology components of hepatic tissue were used to access the prophylactic effects. The antioxidant parameters, cancer preventive agent status, and apoptosis mechanism were reviewed to scrutinize the possible mechanism.

Results: Dose-dependent treatment of GLA significantly $(P<-0.001)$ modulated the hepatic nodules, hepatic, body weight, antioxidant, and non-hepatic parameters. Curiously, the Real-time polymerase chain reaction (RT-PCR) and immunoblotting showed the GLA altered reduced the hypoxic microenvironment, mitochondrial mediated death apoptosis, and anti-inflammsatory pathways.

Conclusion: On the basis of the above results, we can conclude that the GLA exhibited a chemoprotective effect against DEN induced HCC that might be due to the altered hypoxic microenvironment, mitochondrial mediated death apoptosis, and anti-inflammatory pathway, respectively.

Keywords: gamma linolenic acid, apoptosis, hepatocellular carcinoma, diethynitrosamine, gene expression

\section{Introduction}

Deaths due to hepatic cancer are daily on the rise, with multiple reasons of mortality. ${ }^{1}$ Hepatocellular carcinoma (HCC) is the most prominent recognized danger to the hepatic tissue, and it is considered as the third most common reason for HCC death around the World. ${ }^{2,3}$ Cirrhotic liver leads to HCCs, followed by a long duration of liver damage brought on by alcohol, non-alcoholic steatohepatitis, environmental toxicants, and viral hepatitis., ${ }^{2,4}$ The available treatment for hepatic cancer can be counted in terms of chemotherapy, radiotherapy, removal of tissue part, and surgical medication, but the success of the treatment depends on the proper diagnosis and the stage of disease, due to more side-effects and the unfortunate outlook of HCC. ${ }^{5,6}$ If the above discussed treatments fail, the last option for the medicinal practitioner is liver transplantation, but the success rate of liver transplantation is limited and depends on the stage of the HCC. ${ }^{7,8}$ By this process, the unnatural openness of organs prohibits this selection for
Correspondence: Mukesh Kumar Chandra Shekhar Singh College of Pharmacy, Koilaha, G.T. Road, Puramufti, Kausambi, Prayagraj, Uttar Pradesh 212203 , India

Tel +9l 984893848 I

Email phmukesh1980@gmail.com

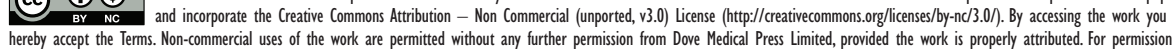
for commercial use of this work, please see paragraphs 4.2 and 5 of our Terms (https://www.dovepress.com/terms.php). 
various people with HCC and increases the risk of tumor reappearance after liver transplantation, obscuring the efficacy of this treatment approach. ${ }^{7-10}$ Thus, it has become the need of the hour for researcher to focus on novel drug discovery with potential therapeutic targets that can be less toxic and can delay or reduce hepatic cancer incidence.

The environmental cancer agent diethyl nitrosamine (DEN), a nitroso compound generally present in nature and various food items such as mixed drinks, cheddar, tobacco, restorative and handled meats, is one of the best sources of a chemical carcinogen, particularly for the liver. It is sometimes found in home detergents and baby feeding nipples. ${ }^{11,12} \mathrm{DEN}$ was found to be the one of the toxicanst to induce hepatic cancer (HCC). It is commonly used in various rodents to induce HCC. ${ }^{13-15}$

Polyunsaturated fatty acids (PUFAs) play an important role in the formation of the cell membrane and also play a significant role in the functioning of membrane fluidity and proteins. They exhibit various cellular, sub-cellular functions, processes, and gene expression. ${ }^{16,17}$ GLA is a member of the $\omega-6$ family of PUFAs and is transfigured into arachidonic acid (AA) via a series of elongation and desaturation reactions. AA is further metabolized via cyclooxygenase (COX) enzymes into the prostaglandins or via 5-lipoxygenase into 5-hydroxy-eicosatetranoic acid and leukotrienes, which shows cellular inflammation. Due to the above facts, GLA is metabolized into the AA, and AA is further metabolized and acts as a pro-inflammatory agent. Due to this mechanism, GLA also acts as a pro-inflammatory in nature. ${ }^{18-21}$

GLA is mostly present in plants such as soy bean, grapes, sunflowers, and fish, and it should be present in the daily diet for a healthy lifestyle. Several researchers suggest that regular intake of GLA reduces the inflammatory reaction and inhibits the cancer and its associated conditions. ${ }^{18,21,22}$ Previous published literature in vitro and in vivo studies suggested the anticancer effect of GLA. GLA reduced tumor growth in a WBC256 rat model; it also inhibited the cell growth of various rat carcinogenesis cell lines and human neuroblastoma cell lines. ${ }^{19,20}$ GLA treatment down-regulated mammary gland carcinogenesis and tumor growth. It is also reduced the growth of various cultured human cell lines such as adenocarcinomic human alveolar basal epithelial cells (A549), human breast cancer cell lines (ZR-75-1), and human prostate cancer cell lines (PC-3). Various researchers suggest that GLA has the potential to have anticancer effects and, in our opinion, few researchers have scrutinized the anticancer effect of GLA against chemically induced HCC.
In the current experimental study, we attempted to explore the anticancer effect of GLA against the DEN-induced HCC and tried to explore the possible mechanism of action.

\section{Materials and methods Drugs and reagents}

GLA, diethylnitrosamine (DEN), Eagle balanced salt solution (EBSS), ponceau $\mathrm{S}$, and RNase were procured from Sigma Aldrich (St Louis, MO, USA). Collagenase type 4, RNase, sodium cacodylate, hematoxylin, and eosin were purchased from Himedia. Bax and Bcl-2 were purchased from Biosynthesis Biotechnology (Beijing, China). The kits for aspartate aminotransferase (AST), alanine aminotransferase (ALT), alpha-fetoprotein (AFP), and alkaline phosphatase (ALP) were purchased from Beihuakangtai Biotechnology (Beijing, China). All other chemical and reagents used in the experimental study were acquired from the reputed vendor.

\section{Experimental protocol}

Swiss Wistar (both sexes; 120-150 gm, body weight) rats were used in the experimental investigation. All the animals were received from the institutional animal house and stored in a single cage (polyethylene) kept at standard experimental conditions $\left(20^{\circ} \mathrm{C} \pm 5^{\circ} \mathrm{C}, 12\right.$ hours light:dark cycle). The animals received standard food diet (China Animal Food, Beijing, China) and water ad libitum. The experimental study was conducted in accordance with the protocol of control and supervision of experiments on animals (CPCSEA), Government of India, and the study had prior approval from the Institutional animal ethics committee (IAEC) of Chandrasheker College of Pharmacy, India (CSP/18/02/018). They were acclimatized for 2 weeks before starting the experimental study. The animals were divided into the following groups, and each group contained 12 animals: Gp I, normal control received only carboxymethyl cellulose (CMC); Gp II, DEN control received a single oral dose of saline; Gp III-V, DEN control received GLA $(0.125,0.25$, and $0.5 \mathrm{~mL} / \mathrm{kg}$, body weight) for the entire study period. All disease control group rats initilly received a single intraperitoneal dose of DEN (200 mg/kg) and every week thereafter received the pheobarbitol dose for induction of HCC. ${ }^{23-25}$ After 1 week of DEN administration, the alpha feto protein (ALP) level was estimated. During the HCC, the level of AFP was boosted more than 10-times as compared to normal.

The food, water, and body weight of all group animals were estimated at regular intervals. After completing the experimental investigation (180 days), the animals were 
sacrificed via dislocation of cervical and hepatic tissues were successfully removed for the further biochemical and histopathological investigation. The blood samples were collected via puncturing the retro orbital plexus.

\section{Morphology and morphometry of hepatocyte nodules}

Hepatic cancer was confirmed by morphological examination by the presence of hepatic nodules. Briefly, the rats were anesthetized by intramuscular injection of ketamine and xylzaine. Hepatic tissue were perfused through the portal vein using the heparinized saline solution, and the hepatic tissue was quickly removed from the group of rats, washed with PBS to remove the blood component from the tissue, and the tissue was blotted using a paper towel, the tissues were then weighed. All the animal tissues were macroscopically scrutinized by checking the color, which showed the development of nodules. The hepatic nodules easily identified, via color (white and gray), differences in size, and those covered with the non-nodular hepatic tissue (reddish brown in color). Further, tissues were evaluated via using the following scale (depending on the size of the hepatic nodules) viz., $\leq 1,1-3$ and $\geq 3.25,26$

\section{Biochemical parameter estimation}

The hepatic parameters, such as serum AFP, ALT, ALP, and AST, non-hepatic parameter viz., total protein, albumin, total bilirubin, direct bilirubin, and blood urea nitrogen (BUN) were estimated from standard kits using the manufacturer instructions.

\section{Antioxidant parameters}

The antioxidant parameters viz., superoxide dismutase (SOD), catalase (CAT), lipid peroxidation (LPO), glutathione (GSH) and glutathione peroxidise (GPx) were determined using the reported method of Kumar et al, with minor modification..$^{25}$

\section{Estimation of caspase level}

Ninety-six well plates were used for the estimation of the level of caspase- 3 and 8 in the different group of rats. Briefly, the serum samples of all group rats were taken into the cuvette followed by adding dithiotheritol (DTT), with a reaction mixture in equal quantity with final addition of DEVD-AFC (caspase 3), IETD-AFC (caspase 8), and it was incubated for 1 hour at room temperature. The free AFC level was estimated by fluorescence technique.

\section{Western blotting}

Briefly, radioimmunoprecipitation assay (RIPA) lysis buffer was used for homogenization of hepatic tissues as per Bradford et al. ${ }^{60}$ Then, Bardford reagent was used for extracting the protein sample via the precipitation method. The blot was incubated overnight with primary antibodies against Bax, Bcl-2, Bcl-xl, BAD, NFkB65, PHD2, UCHL-1, HIF- $1 \alpha$, VDAC, FASN, TNF- $\alpha$, SREBP- $1 \mathrm{c}, \alpha-7 \mathrm{nAChR}$, and HMGB- 1 in $4^{\circ} \mathrm{C}$ and standard ( $\beta$-actin).

\section{qRT-PCR}

For the estimation the qRT-PCR, the primer was designed from the primer tool. Briefly, Trizol reagents were used for the isolation the RNA from the hepatic tissue and the concentration was quantified by the previously reported method with minor modification. Hepatic tissue RNA $(1 \mu \mathrm{g})$ was used in cDNA synthesis in a thermal cycler (96 well) and incubated for 15 minutes at $25^{\circ} \mathrm{C}, 100$ minutes at $85^{\circ} \mathrm{C}$, and 1,140 minutes at $37^{\circ} \mathrm{C}$. cDNA ( $\left.125 \mathrm{ng}\right)$ was added in the reaction of qRT-PCR along with $\beta$-actin (standard reference). After that the program was again incubated for 2 seconds at $50^{\circ} \mathrm{C}$ and 10 seconds at $95^{\circ} \mathrm{C}$ and finally 20 seconds at $58^{\circ} \mathrm{C}$, and the expression was calculated via the $2^{-\Delta \Delta C T}$ method with minor modification.

\section{Statistical analysis}

The result obtained in the current experimental studies was expressed as mean $\pm \operatorname{SEM}(\mathrm{n}=12)$. One-way ANOVA was used to obtain the statistics, followed by least significant difference. $P<0.05, P<0.01$, and $P<0.001$ were considered as significant, more significant, and most significant, respectively.

\section{Results \\ Effect of GLA on morphology and morphometry of hepatocyte nodules}

The GLA treatment inhibits the morphology and morphometry of hepatocyte nodules of DEN-induced HCC rats (data not included in the manuscript). Normal control and GLA $(0.5 \mathrm{~mL} / \mathrm{kg})$ did not exhibit the formation of any type of hepatic nodule formation. DEN-induced group rats showed the expansion of hepatic nodules which are white and grayish white in color. Table 1 exhibits the total number of hepatic nodules (252) in the DEN group, and GLA treatment significantly reduced the incidence of hepatic nodules $(189,102$, and 35 ) at doses of $0.125,0.25$, and $0.5 \mathrm{~mL} / \mathrm{kg}$, respectively. The DEN group showed the hepatic nodules 115, 72, and 65 at a size of $\leq 1 \mathrm{~mm}, 1-3 \mathrm{~mm}$, and $\geq 3 \mathrm{~mm}$, respectively. 
Table I Effect of GLA on the development of macroscopic hepatocytes nodules induced by DEN in rats

\begin{tabular}{|l|l|l|l|l|}
\hline S. No. & Groups & $\begin{array}{l}\text { Number of rats/number } \\
\text { of rats with nodules }\end{array}$ & $\begin{array}{l}\text { Total number } \\
\text { of nodules }\end{array}$ & $\begin{array}{l}\text { Tumor } \\
\text { incidence (\%) }\end{array}$ \\
\hline I & DEN control & $10 / 10$ & 252 & 100 \\
\hline 2 & DEN control+GLA $(0.125 \mathrm{~mL} / \mathrm{kg})$ & $11 / 10$ & 189 & 90.90 \\
\hline 3 & DEN control+GLA $(0.25 \mathrm{~mL} / \mathrm{kg})$ & $10 / 6$ & 102 & 60 \\
\hline 4 & DEN control+GLA $(0.5 \mathrm{mg} / \mathrm{kg})$ & $9 / 2$ & 35 & 22.22 \\
\hline
\end{tabular}

Note: Group I (normal control) and Group II (normal control+GLA $0.5 \mathrm{mg} / \mathrm{kg}$ ) did not show any visible hepatocytes nodule.

Abbreviations: GLA, gamma linolenic acid; DEN, diethylnitrosamine.

The GLA treatment group inhibited the incidence of hepatic nodules $83(\leq 1 \mathrm{~mm}), 70(1-3 \mathrm{~mm})$, and $36(\geq 3 \mathrm{~mm})$ at a dose of $0.125 \mathrm{~mL} ; 46$ ( $\leq 1 \mathrm{~mm}), 35(1-3 \mathrm{~mm})$, and 21 ( $\geq 3 \mathrm{~mm})$ at a dose of $0.25 \mathrm{~mL} / \mathrm{kg}$; and $23(\leq 1 \mathrm{~mm}), 8(1-3 \mathrm{~mm})$, and $4(\geq 3 \mathrm{~mm}$ ) at a dose of $0.5 \mathrm{~mL} / \mathrm{kg}$, respectively (Table 2 ).

\section{Effect of GLA on the body weight}

Body weight is a significant parameter for the estimation of disease effect. The same data was observed in our experimental study. DEN group rats showed increased body weight $(279.83 \pm 5.34)$ as compared to initial body weight (138.74 \pm 4.81 ), but in comparison to the other group the body weight of DEN group rats was decreased. GLA treatment showed increased body weight (139 \pm 3.82$)$ to $(303.74 \pm 6.78)$ at a dose of $0.125 \mathrm{~mL} / \mathrm{kg} ;(131 \pm 4.04)$ to $(322.38 \pm 5.93)$ at a dose of $0.25 \mathrm{~mL} / \mathrm{kg}$, and $(132.74 \pm 4.23)$ to $(375 \pm 8.93)$ at a dose of $0.5 \mathrm{~mL} / \mathrm{kg}$ (Figure 1A).

The liver weight and relative liver weight of normal control and GLA $(0.5 \mathrm{~mL} / \mathrm{kg})$ showed an almost similar trend. DEN group rats showed increased liver tissue weight due to expansion of hepatic nodules, and the increase in weight of hepatic tissue in this group showed an increase in relative liver weight. Concentration-dependent treatment of GLA exhibited reduced liver tissue weight and relative tissue weight as companion to DEN group rats (Figure 1B).

\section{Effect of GLA on hepatic parameters}

Several researchers suggest that the AFP is the gold parameter and consider it as the indicator for the hepatic cancer. During the HCC condition, hepatic parameters boosted a significant level into the serum due to leakage into blood. DEN rats exhibited the upregulation of AFP (305.84 \pm 0.394$)$, AST

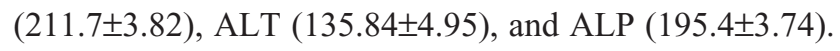
Concentration-dependent treatment of GLA significantly reduced the level of hepatic parameters near tot the normal control (Figure 2).

\section{Effect of GLA on non-hepatic parameters}

A similar trend (hepatic parameters) was found in the nonhepatic parameters. DEN-induced group rats demonstrated the level of non-hepatic parameters like albumin ( $0.85 \pm 0.03)$, total protein $(2.4 \pm 0.12)$, BUN $(40 \pm 3.91)$, total bilirubin (77.5 \pm 4.83$)$, and direct bilirubin (21.02 \pm 1.92$)$. GLA treatment altered the level of non-hepatic parameters like albumin (3.92 \pm 0.23$)$, total protein (7.5 \pm 0.92$)$, BUN (13.25 \pm 2.83$)$, total bilirubin (14.5 \pm 3.55$)$, and direct bilirubin $(7.74 \pm 1.83)$ (Figure 3).

\section{Effect of GLA on antioxidant parameters}

Figure 4 demonstrates the antioxidant effect of GLA on all groups of rats. A concentration-dependent treatment of GLA restored the antioxidant level near to the normal control level. GLA successfully down-regulated the level of LPO (8.1 \pm 1.45$)$ and upregulated the level of CAT (0.65 \pm 0.004$)$, SOD (1.36 \pm 0.08$)$, GST (0.31 \pm 0.002$)$, and GPx (5.8 \pm 0.18$)$, as compared to DEN-treated rats.

\section{GLA effect on caspase}

During the HCC disease, the level of caspase considerably decreased due to an increase in the inflammatory reactions.

Table 2 Effect of GLA on the size distribution and growth of hepatocyte nodules induced by DEN in rats

\begin{tabular}{|c|c|c|c|c|c|c|}
\hline \multirow[t]{2}{*}{ S. No. } & \multirow[t]{2}{*}{ Groups } & \multirow{2}{*}{$\begin{array}{l}\text { Total number } \\
\text { of nodules }\end{array}$} & \multirow{2}{*}{$\begin{array}{l}\text { Average number of nodules/ } \\
\text { nodules bearing rats }\end{array}$} & \multicolumn{3}{|c|}{ Relative size (\% of number size) } \\
\hline & & & & $\leq \mathbf{I ~ m m}$ & $\mathrm{I}-3 \mathrm{~mm}$ & $\geq 3 \mathrm{~mm}$ \\
\hline 1 & DEN control & 252 & $40.23 \pm 4.37$ & $115(45.64)$ & $72(28.57)$ & $65(25.69)$ \\
\hline 2 & DEN control+GLA $(0.125 \mathrm{~mL} / \mathrm{kg})$ & 189 & $28.34 \pm 3.05$ & $83(43.91)$ & $70(37.07)$ & $36(19.15)$ \\
\hline 3 & DEN control+GLA $(0.25 \mathrm{~mL} / \mathrm{kg})$ & 102 & $16.93 \pm 1.62$ & $46(45.09)$ & $35(34.31)$ & $21(20.58)$ \\
\hline 4 & DEN control+GLA (0.5 mg/kg) & 35 & $6.04 \pm 2.93$ & 23 (65.7I) & $8(22.86)$ & $4(11.94)$ \\
\hline
\end{tabular}

Note: Group I (normal control) and Group II (normal control+GLA $0.5 \mathrm{mg} / \mathrm{kg}$ ) did not show any visible hepatocytes nodule. Abbreviations: GLA, gamma linolenic acid; DEN, diethylnitrosamine. 

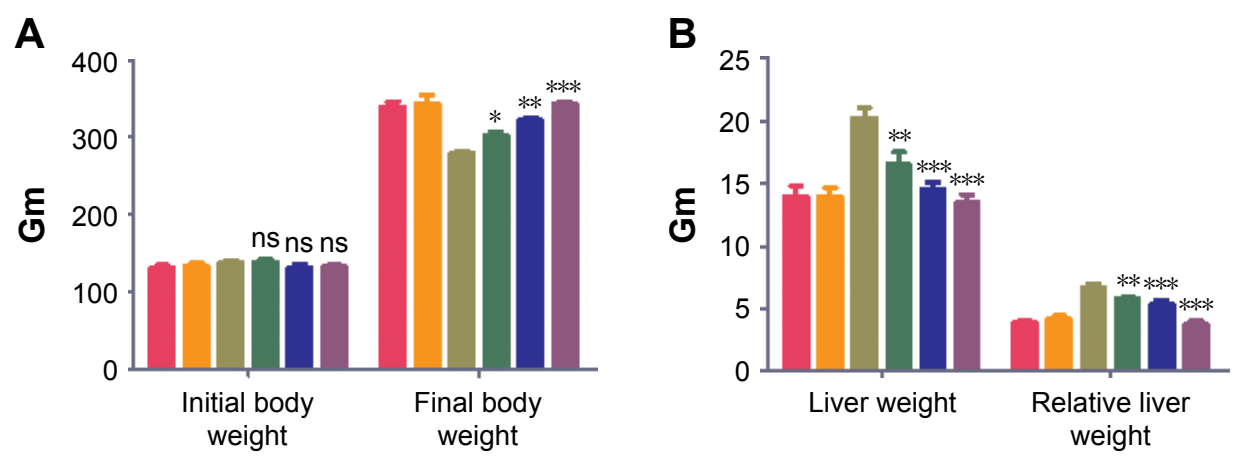

\begin{tabular}{|c|c|c|c|}
\hline $\mathrm{NC}$ & $\mathrm{NC}+\mathrm{GLA}(0.50 \mathrm{~mL} / \mathrm{kg})$ & DEN & DEN+GLA $(0.125 \mathrm{~mL} / \mathrm{kg})$ \\
\hline DEN & \multicolumn{3}{|c|}{$\mathrm{DEN}+\mathrm{GLA}(0.5 \mathrm{~mL} / \mathrm{kg})$} \\
\hline
\end{tabular}

Figure I Effect of GLA on body weight and tissue weight.

Notes: (A) The initial body weight and final body weight of all group rats, and (B) the hepatic tissue and relative tissue weight method as described in the Materials and methods section. All values are presented as mean \pm SEM. Statistical analysis by one-way ANOVA followed by Dunnett's multiple comparison. $* P<0.05$, $* * P<0.01$ and $* * * P<0.001$.

Abbreviations: ns, non-significant; DEN, diethylnitrosamine; GLA, gamma linolenic acid; NC, normal control.

GLA treatment significantly $(P<0.001)$ increased the level of caspase-3 and -7 in a dose-dependent manner (Figure 5).

\section{GLA boosted apoptosis in hepatic tissue}

Figure 6 represents the quantitative real time PCR results explaining the critical boosting level of mRNA expression of antiapoptotic proteins and proapototic markers. DEN treatment boosted the mitochondria mediated apoptosis (cytochrome c, VADC, pro-caspase 9, and Apaf-1), along with the upregulation of cytochorme cexpression (Figure 6).

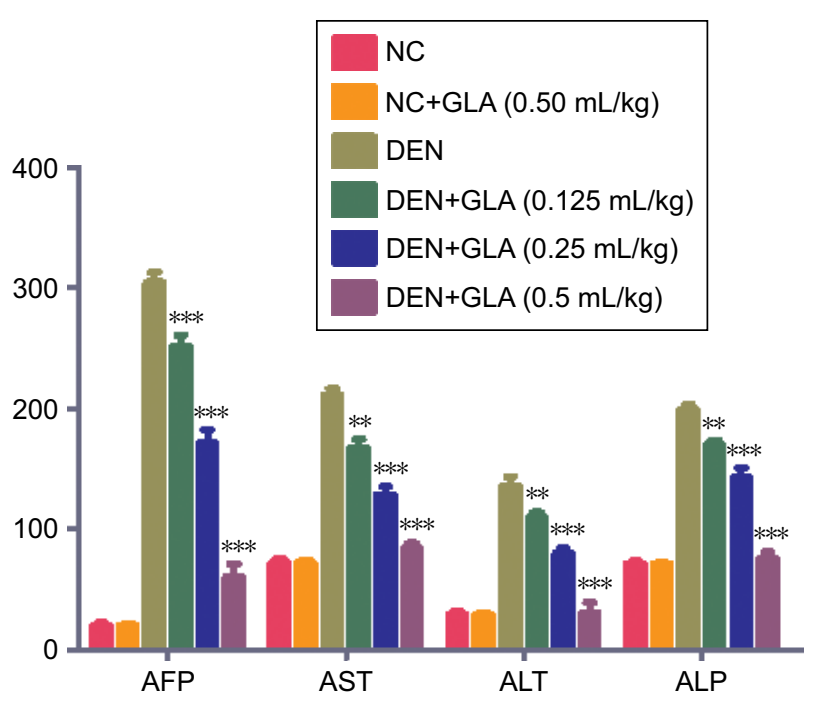

Figure 2 The effect of GLA on hepatic parameters of all group rats, for AFP, AST, ALT, and ALP, as described in the Materials and methods section.

Notes: All values are presented as mean \pm SEM. Statistical analysis by one-way ANOVA followed by Dunnett's multiple comparison. $* P<0.05$, $* * P<0.01$, and $* * * P<0.001$.

Abbreviations: AFP, Alpha feto protein; ALP, Alkaline phosphatase; ALT, Alanine Aminotransferase; AST, Aspartate Aminotransferase; DEN, diethylnitrosamine; GLA, gamma linolenic acid.
A similar trend was found in the Western blot (Figure 7). GLA treatment significantly protects the cell from apoptosis. DEN treatment also afforded commendable hypoxia, which was perceived via boosting the HIF-1 $\alpha$, FASN, UCHL-1, SREBP-1c, and NFאBp65, along with reducing PHD2 expression (Figures 8 and 9).

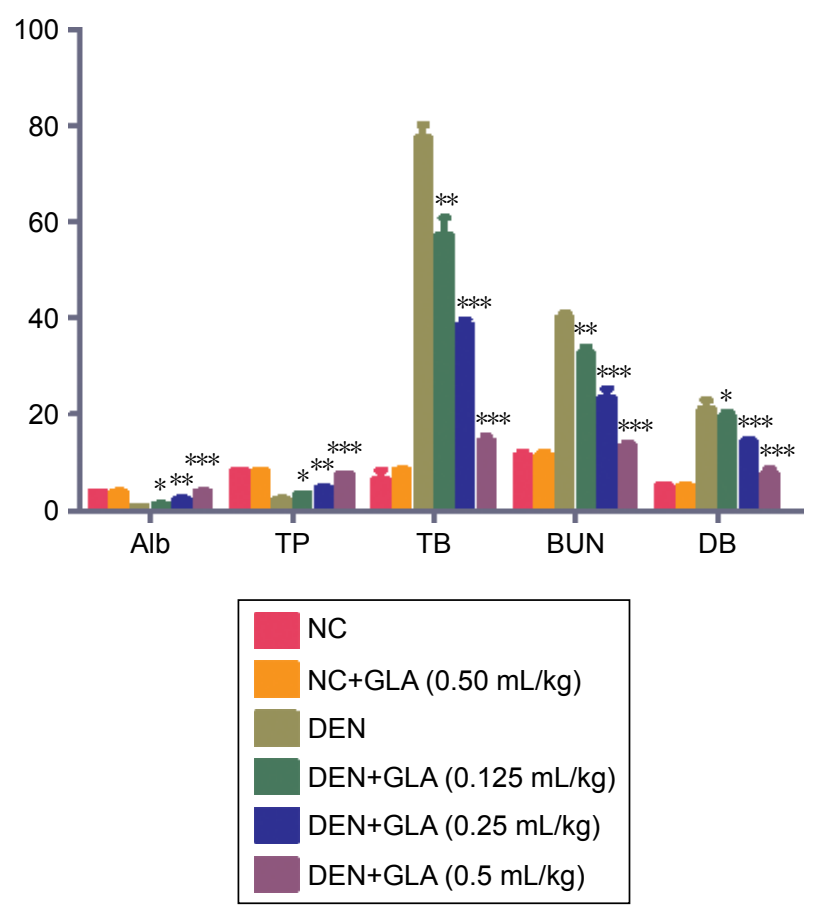

Figure 3 The effect GLA on non-hepatic parameters of all group rats, for Alb, TP, TB, BUN, and DB, as described in the Materials and methods section.

Notes: All values are presented as mean \pm SEM. Statistical analysis by one-way ANOVA followed by Dunnett's multiple comparison. $* P<0.05, * * P<0.01$ and $* * * P<0.001$.

Abbreviations: Alb, Albumin; BUN, Blood urea nitrogen; DB, Direct bilirubin; DEN, diethylnitrosamine; GLA, gamma linolenic acid; NC, normal control; TB, Total bilirubin; TP, Total protein. 


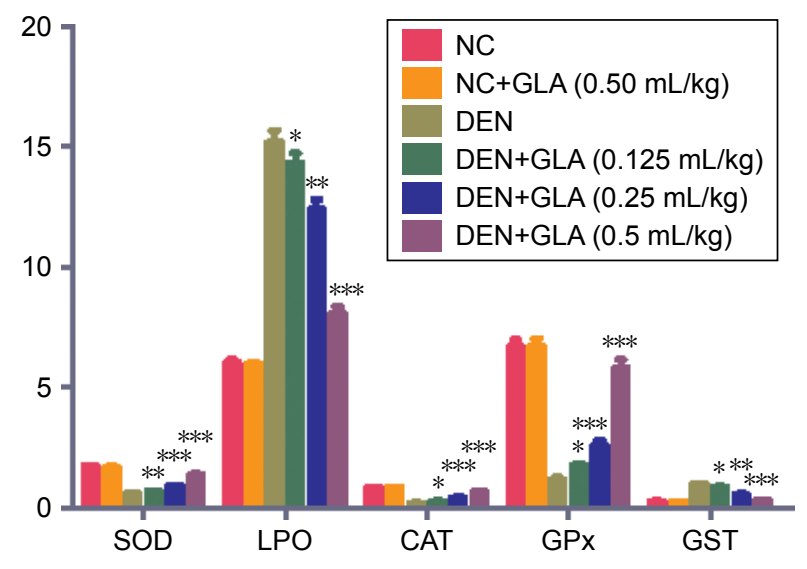

Figure 4 The effect of GLA on antioxidant parameters of all group rats, for SOD, LPO, CAT, GPx, and GST, as described in Materials and methods section. Notes: All values are presented as mean \pm SEM. Statistical analysis by one-way ANOVA followed by Dunnett's multiple comparison. $* P<0.05$, $* * P<0.01$ and $* * * P<0.00$ I. Abbreviations: CAT, Catalase; DEN, diethylnitrosamine; GLA, gamma linolenic acid; GPx, Glutathione peroxidase; GST, Glutathione S-transferase; LPO, Lipid peroxidation; NC, normal control; SOD, Superoxide dismutase.

\section{Discussion}

HCC is the most common malignancy in among all types of malignancies. The developed, as well as undeveloped countries are affected by this disease. It is considered as the most common hepatic cancer disease due to the late signs of diagnosis. Various factors, such as high consumption of ethanol, hepatitis (B and C), and aflatoxin, are various pathogens involved in the progression of disease. Generally HCC is induced via fungal poison, chemical poison, and food contamination. ${ }^{2,3}$ DEN (nitroso compound) is most commonly used to induce hepatic cancer, which induces the HCC in rodents similarly to in humans. In the current investigation, we used the DEN and phenobarbital to induce HCC in Wistar rats and we observed that DEN group rats showed the generation of hepatic nodules and dose-dependent treatment of GLA significantly $(P<0.001)$ down-regulated the formation of these hepatic nodules. ${ }^{27,28}$ The available literature suggests that the formation of pre-cancerous hepatic nodules is the precursor of hepatic cancer. The dosedependent treatment of GLA significantly reduced the formation of pre-cancerous hepatic nodules and suggests the chemoprotective effect of GLA on HCC.

Body weight, tissue weight, and relative tissue weight are significant parameters to estimate the expansion of the cancer disease. Several researchers suggest that, during the progression of disease, body weight reduced, and a similar result was found in our experimental study. ${ }^{29}$ DEN group rats showed that reduced body weight, as compared to the other group rats, and dose-dependent treatment of GLA significantly $(P<0.001)$ increased the body weight in a dose-dependent manner. Other parameters, such as relative liver weight, significantly increased in the DEN group rats due to expansion of hepatic nodules, and GLA treatment significantly $(P<0.001)$ decreased the relative hepatic weight. On the basis of this result, we can say that GLA increases the body weight and relative tissue weight. The current hypothesis was supported by a reduction of the tumor formation in GLA treatment group rats.

Biochemical markers plays an important role in screening specific conditions of malignancy and help with treatment start, hypothesis advancement observing, and finally evaluation of reactions for treatment. ${ }^{30,31}$ These catalysts are extraordinary, and changes in their level/concentration directly showed the effect on the cell multiplication with expansion of potential and their metabolic turnover. ${ }^{32,33}$ The alterations of the activity of these enzymes have been showed to relate well with the

B
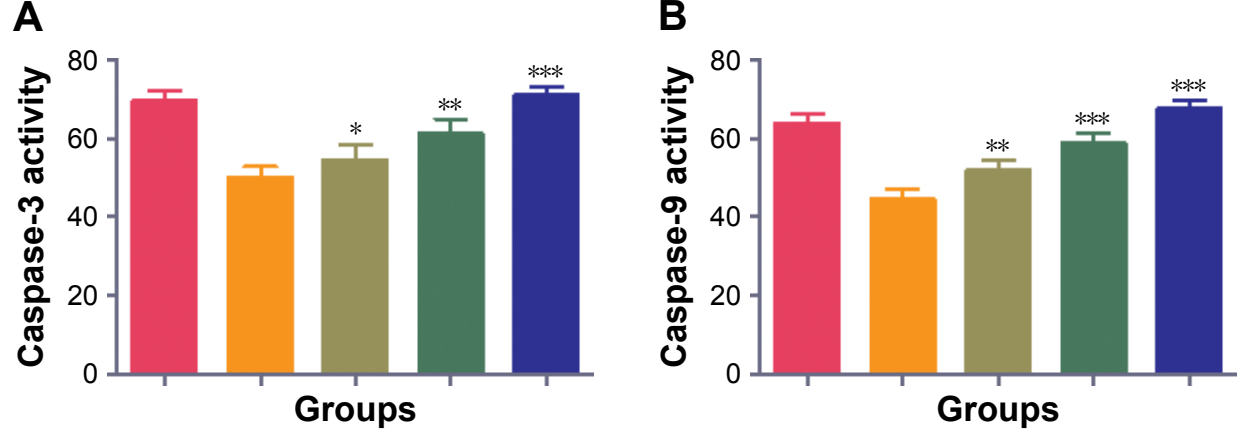

\begin{tabular}{|c|c|}
\hline DEN & $\mathrm{DEN}+\mathrm{GLA}(0.125 \mathrm{~mL} / \mathrm{kg})$ \\
\hline DEN+GLA (0.25 mL/kg) & $\mathrm{DEN}+\mathrm{GLA}(0.5 \mathrm{~mL} / \mathrm{kg})$ \\
\hline
\end{tabular}

Figure 5 The effect of GLA on caspase.

Notes: $(\mathbf{A})$ caspase-3 and $(\mathbf{B})$ caspase- 8 , as described in the Materials and methods section. All values are presented as mean \pm SEM. Statistical analysis by one-way ANOVA followed by Dunnett's multiple comparison. $* P<0.05$, $* * P<0.0$ l, and $* * * P<0.001$.

Abbreviations: DEN, diethylnitrosamine; GLA, gamma linolenic acid; NC, normal control. 
A

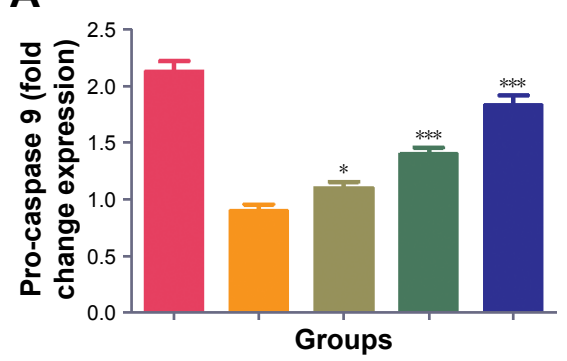

D

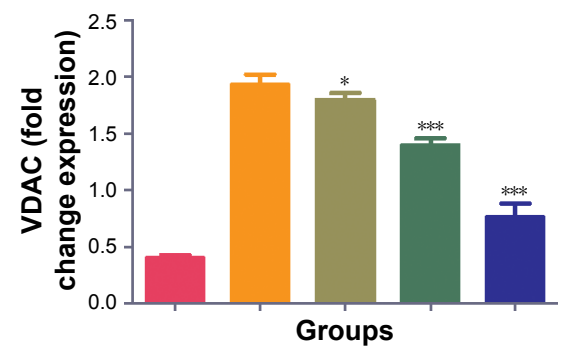

G

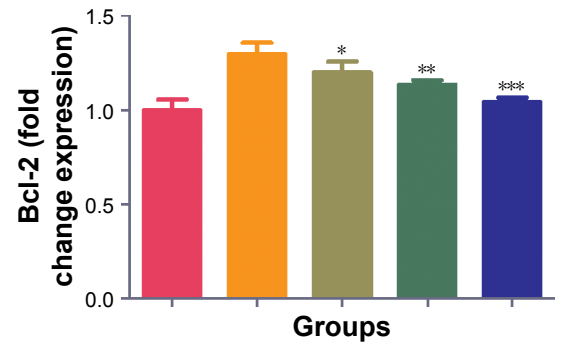

B

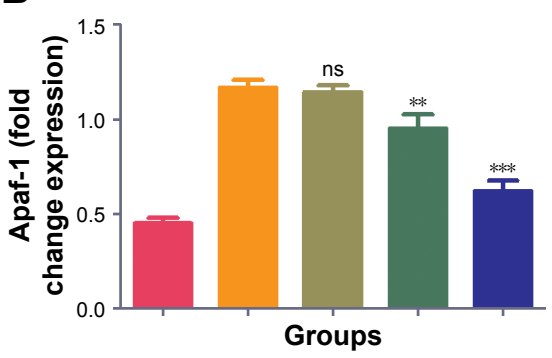

E

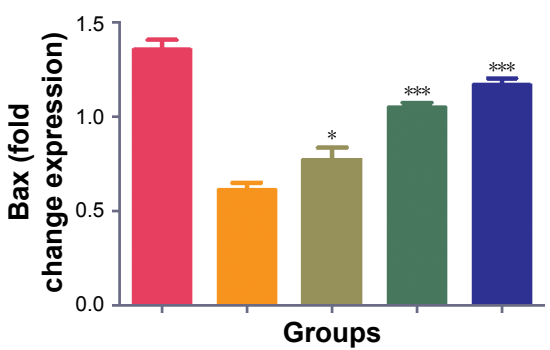

H

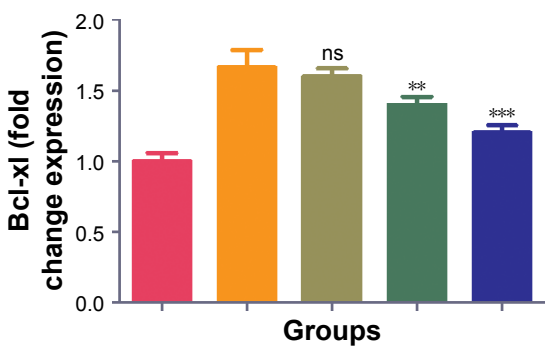

C

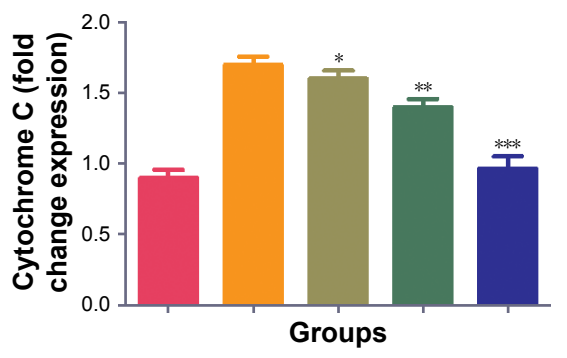

$\mathbf{F}$

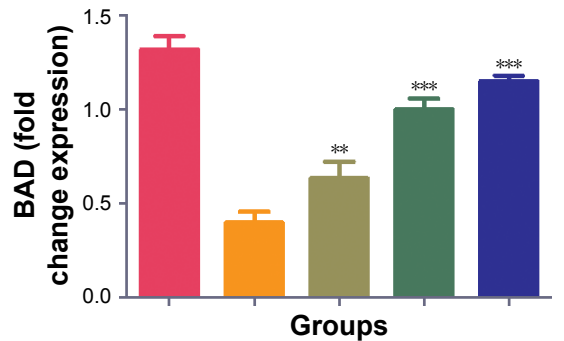

Figure 6 The effect of GLA on activation of mitochondrial mediated pathway.

Notes: (A) Pro-caspase 9, (B) Apaf-I, (C) Cytochrome C, (D) VDAC, (E) Bax, (F) BAD, (G) Bcl-2, and (H) Bcl-xl, as described in the Materials and methods section. All values are presented as mean \pm SEM. Statistical analysis by one-way ANOVA followed by Dunnett's multiple comparison. $* P<0.05$, $* * P<0.01$, and $* * * P<0.001$.

Abbreviations: DEN, diethylnitrosamine; GLA, gamma linolenic acid; NC, normal control; ns, non-significant.

quantities changed in the cells during the malignancy condition. During the malignancy condition, there is a disorder of transport function, which is performed via cell organelles of hepatocytes. During the cancer, the enzymes start to secrete into the circulation and modulate the content in the serum due to alteration of plasma membrane permeability. ${ }^{34,35}$ The increase in enzymes into the circulation due to damage of the cell structure and its integrity alters the enzymatic concentration. Serum enzymes like ALP and transaminases are used as an indicator in liver damage. DEN group rats showed an increased level of ALT, AST, and ALP and suggest the dysfunction of hepatic tissue. Transaminases enzymes viz., AST and ALT are both directly co-related to conversion of amino acid to keto acids and play a significant role in the expansion of HCC. ${ }^{36}$ GLA treatment shows the inhibitory effect of DEN-induced boosted enzymatic activity, which is avowed via GLA and protects the liver from harm.

AFP is an oncofetal protein, considered as an indicator for hepatic cancer. During the disease, the content of AFP considerably boosts, and this is also used as a specific tool for the estimation of HCC. ${ }^{37,38}$ AFP is clinically utilized for diagnosis of tumor markers. The introduction of specific cancer inducing agents, eg, DEN, has been found to increase the concentration of AFP to a significant level. ${ }^{39,40}$ The concentration of AFP was lower during the birth but, during the HCC, the concentration of AFP considerably enhanced in HCC patients. A similar momentum was observed in our experimental study, DEN-induced group rats exhibited an increased level of AFP, which was significantly $(P<0.001)$ down-regulated by the GLA treatment dose-dependently.

Another way to treat the disease is to scavenge the free radical. During the $\mathrm{HCC}$, the free radical is induced by DNA and expands the toxic reactions. DEN induces the alteration of DNA structure, especially the expansion of alkyl DNA, and causes chromosomal abnormalities, additionally it induces the micronuclei in hepatic tissue. ${ }^{41,42}$ Most of the drug metabolizes into the liver, and DEN also digests into the hepatic tissue; during the DEN digestion it releases a lot of free radical or reactive oxygen species, which are involved in the different stages of carcinogenesis 


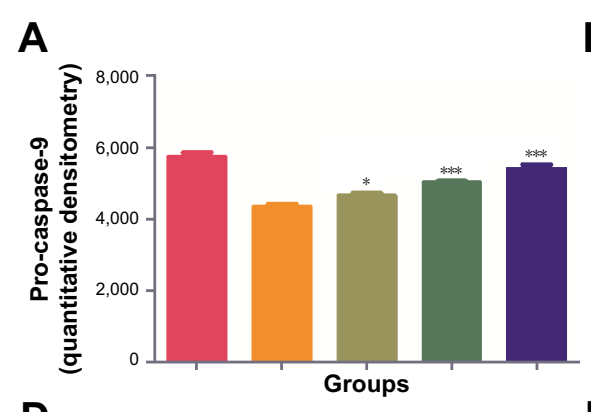

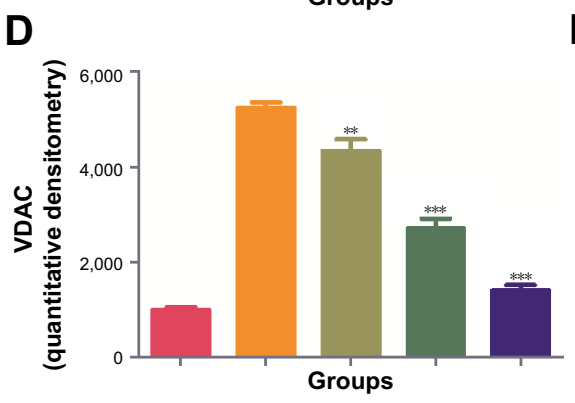

$\mathbf{G}$
B

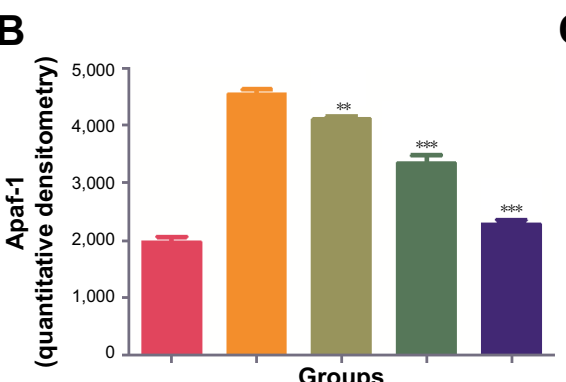

E

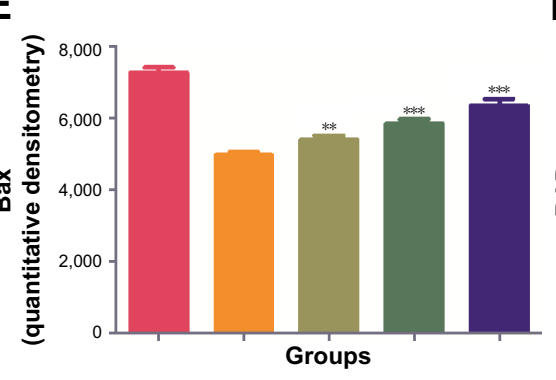

$\mathrm{H}$
C

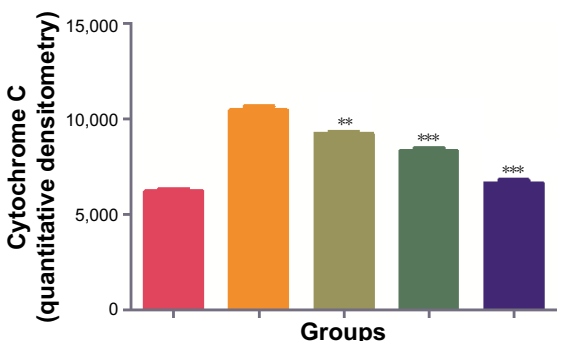

F

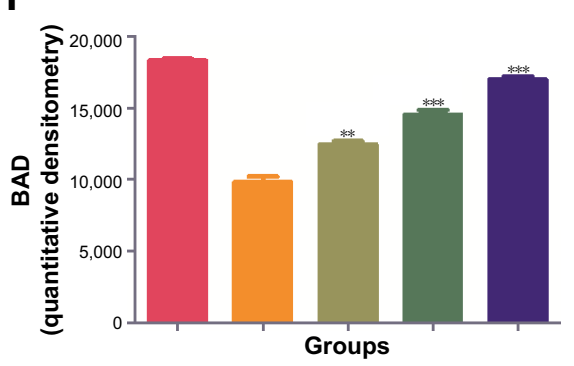

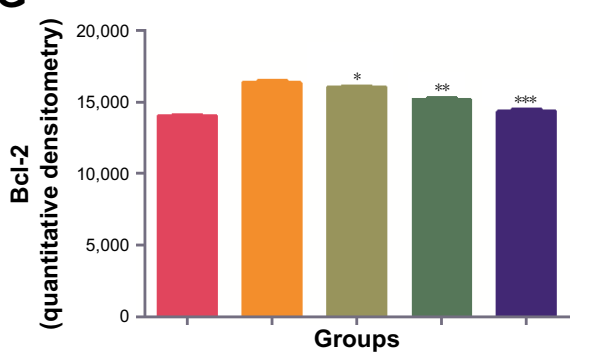

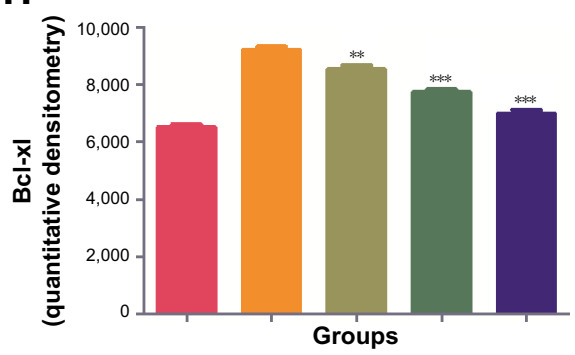

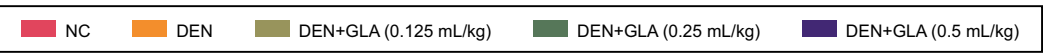

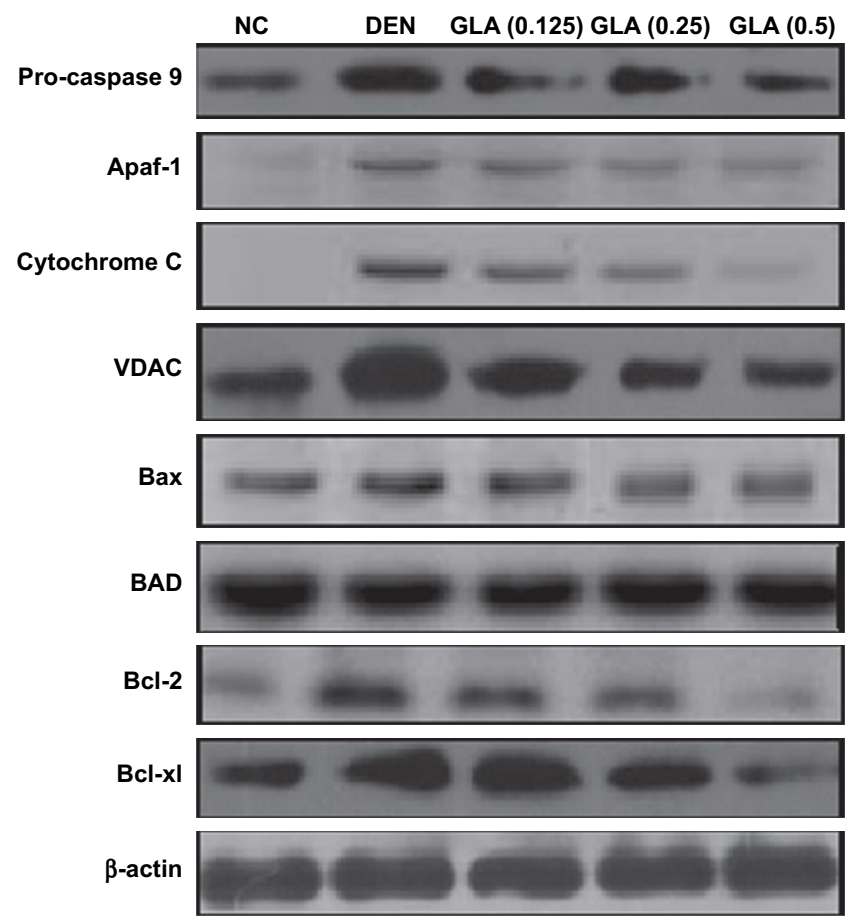

Figure 7 The effect of GLA on activation of mitochondrial mediated pathway via immunoblotting assay.

Notes: (A) Pro-caspase 9, (B) Apaf-I, (C) Cytochrome C, (D) VDAC, (E) Bax, (F) BAD, (G) Bcl-2, and (H) Bcl-xl, as described in the Materials and methods section. All values are presented as mean \pm SEM. Statistical analysis by one-way ANOVA followed by Dunnett's multiple comparison. $* P<0.05$, $* * P<0.01$ and $* * * P<0.00 \mathrm{I}$.

Abbreviations: DEN, diethylnitrosamine; GLA, gamma linolenic acid; NC, normal control. 
A

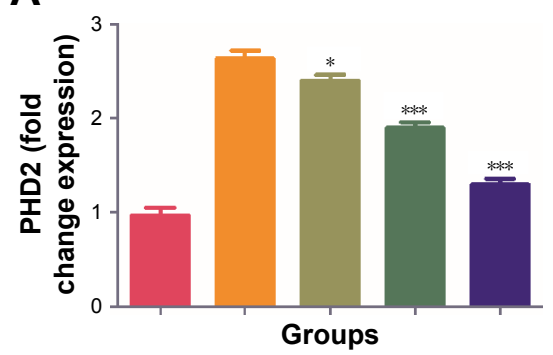

D

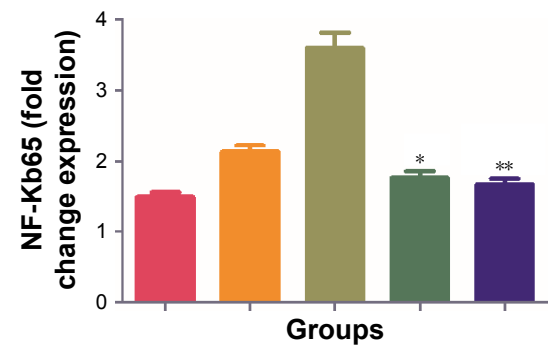

B

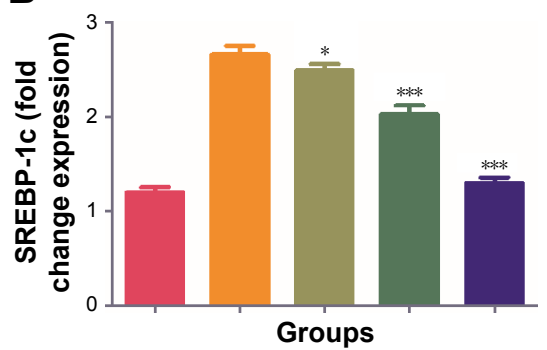

E

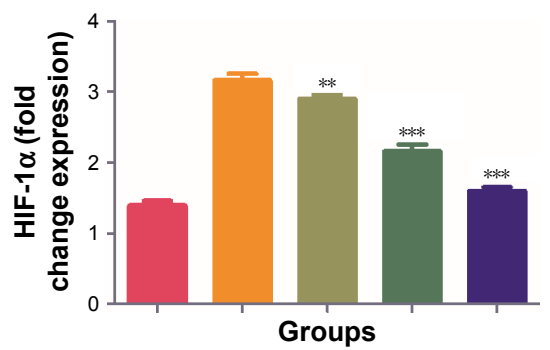

C

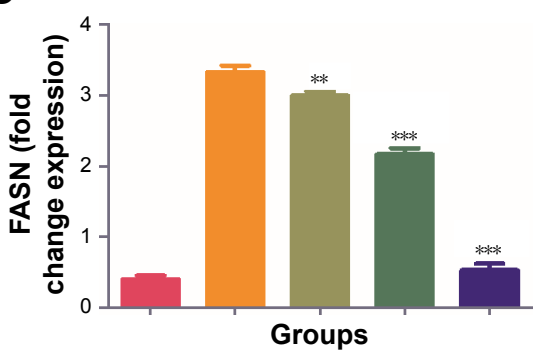

$\mathbf{F}$

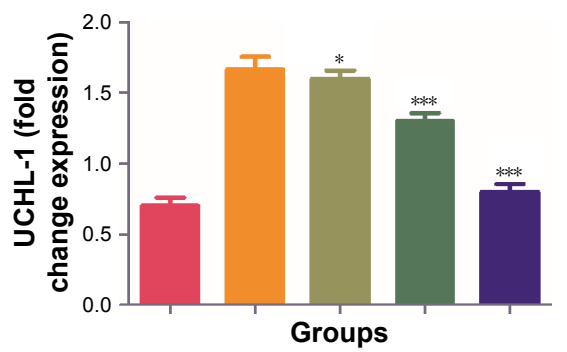

$\begin{array}{llll}\text { NC } & \text { DEN } & \text { DEN+GLA }(0.125 \mathrm{~mL} / \mathrm{kg}) & \mathrm{DEN}+\mathrm{GLA}(0.25 \mathrm{~mL} / \mathrm{kg}) \\ \mathrm{DEN}+\mathrm{GLA}(0.5 \mathrm{~mL} / \mathrm{kg})\end{array}$

Figure 8 The effect of GLA on activation of hypoxic cancer cells metabolic pathway.

Notes: (A) PHD2, (B) SREBP-Ic, (C) FASN, (D) NF-Kb65, (E) HIF-I $\alpha$, and (F) UCHL-I, as described in the Materials and methods section. All values are presented as mean \pm SEM. Statistical analysis by one-way ANOVA followed by Dunnett's multiple comparison. $* P<0.05, * * P<0.01$ and $* * * P<0.00 \mathrm{I}$.

Abbreviations: DEN, diethylnitrosamine; GLA, gamma linolenic acid; NC, normal control.

via initiation, expansion, and progression. ${ }^{43}$ It alters the endogenous antioxidant redox system and induces a disturbance in the endogenous redox systems. ${ }^{44}$ It also starts the deposition of protein and lipid into the hepatic tissue and decreases the membrane micro-viscosity of hepatic cells. Various cellular components, such as DNA, lipids, carbohydrates, low molecular weight compound, and thiol, attract to the ROS and start the oxidation of macromolecules and finally expand the pathogenesis of disease. MDA, an indicator of LPO, is a prominent marker of oxidative stress and increasing the concentration of MDA suggests an increase in oxidative stress via DEN, which was activated..$^{45}$ An increase in MDA level starts damaging the cells, initiates cell death, induces oxidative stress, generates ROS, and alters cellular function finally a carcinogenesis. During the induction of disease, LPO starts the production of peroxy and alkoxy radicals, which results in dysfunction of the antioxidant system. The role of the endogenous antioxidant system is to scavenge the free radical and toxic effect of free radicals. ${ }^{46}$ SOD and CAT are both first line endogenous antioxidant enzymes, which play a significant role in protecting the cell from the free radical via scavenging the superoxide into hydrogen peroxide and detoxification of the hydrogen peroxide. ${ }^{47}$ During the disease, the levels of SOD and CAT both decline, and dose-dependent treatment of GLA significantly $(P<0.001)$ increases the MDA level as compared to DEN control and suggests the antioxidant effect of GLA.

Angiogenesis and cell proliferation play significant roles in cancer progression. ${ }^{48,49}$ Both mechanisms have a substantial role in the tissue architecture and the same is found in the morphological evaluation. ${ }^{50}$ The apoptosis can be defined via two pathways, such as mitochondrial intrinsic and death receptor mediated apoptotic pathways. Bcl-2 family protein regulates the mitochondrial pathway via involvement of pro- and antiapoptotic protein members. During the apoptosis process, $\mathrm{BAD}$ and BAX (proapoptotic) protein translocate into the mitochondria outer membrane and boost the secretion of cytochrome c. ${ }^{51,52}$ On the contrary, Bcl-2 and BCL-XL (antiapoptotic) proteins down-regulate the secretion of cytochrome $\mathrm{C} .^{50}$ In the current experimental study, we observed that the GLA treatment enhanced the expression of Bcl-2 and BCL-XL (antiapoptotic) and decreased the expression of BAD and BAX (proapoptotic). The same momentum was observed in the mRNA expression estimated via q-RT-PCR. Cytochrome c secretion triggers the congregation of cytochrome apoptosome and apoptosome is consider as the complex form of cytochrome-c, procaspase 9, and Apaf-1. The formation of apoptosome reduces the cytosolic level of pro-caspase-9 and Apaf-1. A similar result was observed in our experimental study, and the expression of VDAC and cytochrome $\mathrm{c}$ is reduced during progress of the disease. We found cleavage 
A
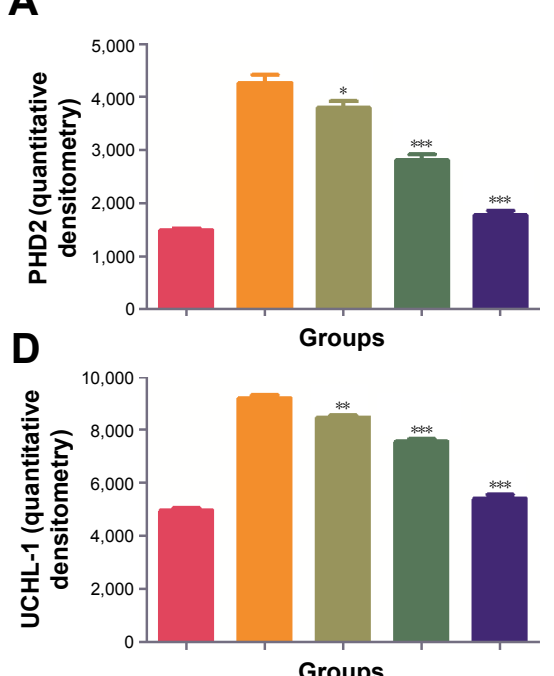

B

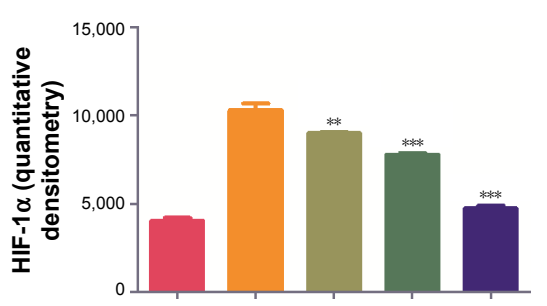

E

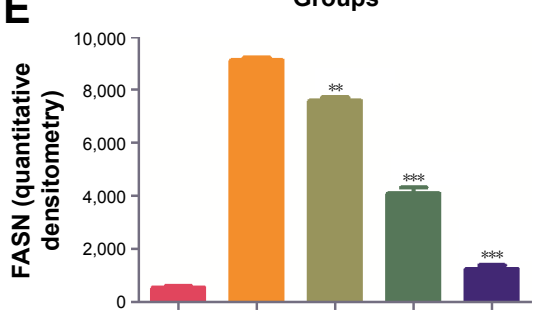

Groups
C

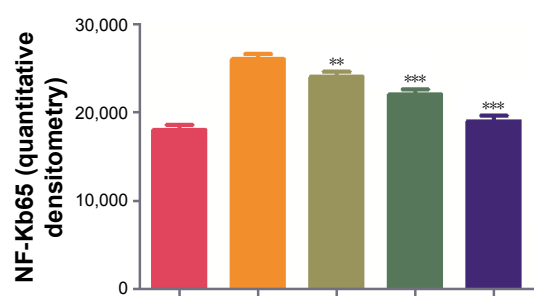

$\mathbf{F}$

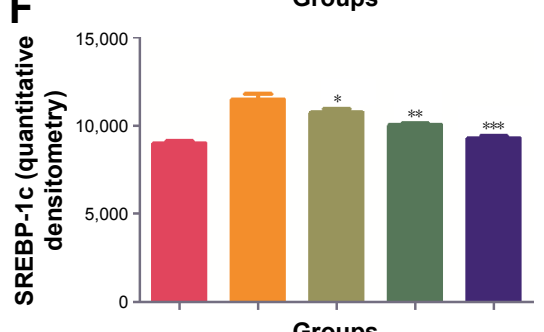

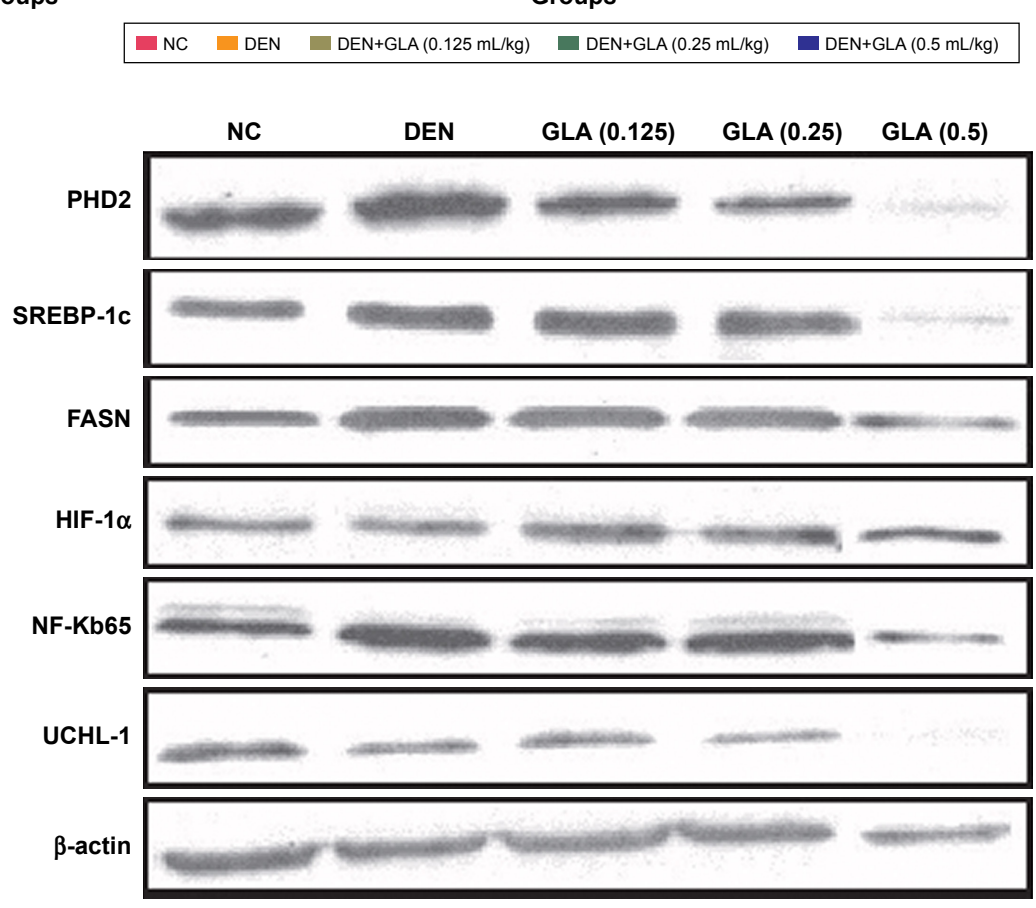

Figure 9 The effect of GLA on activation of hypoxic cancer cells metabolic pathway via immunoblotting assay.

Notes: (A) PHD2, (B) HIF-I $\alpha$, (C) NF-Kb65, (D) UCHL-I, (E) FASN and (F) SERBC-Ic, as described in the Materials and methods section. All values are presented as mean \pm SEM. Statistical analysis by one-way ANOVA followed by Dunnett's multiple comparison. $* P<0.05, * * P<0.01$ and $* * * P<0.001$.

Abbreviations: DEN, diethylnitrosamine; GLA, gamma linolenic acid; NC, normal control.

of procaspase 9 with the generation of apoptosome and lead the caspase 9 formation, which further activated the caspase 3 and $8 .{ }^{53}$ The activation of caspase starts the activation of a downstream caspase cascade leading to apoptosis. On the basis of the result, we can say that GLA treatment reduced the proliferative and angiogenic effect of DEN via activation of a mitochondrial mediated apoptosis pathway.

It is well documented that tumor cells want energy from the glycolysis due to the hypoxic condition of cells. ${ }^{54}$ Previous published literature suggests that enhanced glycolytic activity in tumor cells boost the synthesis of fatty acid, which is required via de novo fatty acid synthesis. ${ }^{55,56}$ Hypoxia regulates via HIF- $1 \alpha$ and also regulates via PHD2 (iron dependent hydroxylases enzyme) and 2-oxoglutarate. ${ }^{57}$ The HIF- $1 \alpha$ expression significantly reduces and confirms down-regulation of UCHL-1 and NF-kBp65 expression. ${ }^{58,59}$ Concentration-dependent treatment of GLA inhibits the expression of SREBP-1 and FASN (marker of de nova fatty acid synthesis). We can say that GLA down-regulated the DEN induced hypoxia and protected rodent HCC. 


\section{Conclusion}

Henceforth, On the basis of this result, we can conclude that GLA exhibited a chemoprotective effect against the DEN induced HCC via a regulated hypoxia induced cell signaling pathway, anti-inflammatory pathway, and mitochondria mediated death apoptosis.

\section{Abbreviations}

HCC, hepatocellular carcinoma; GLA, gamma linolenic acid; DEN, diethylnitrosamine; RT-PCR, real-time polymerase chain reaction; PUFAs, polyunsaturated fatty acids; AA, arachidonic acid; COX, cyclooxygenase; EBSS, eagle balanced salt solution; AST, aspartate aminotransferase; ALT, alanine aminotransferase; AFP, alpha-fetoprotein; ALP, alkaline phosphatise; CMC, carboxymethyl cellulose; SOD, superoxide dismutase; CAT, catalase; LPO, lipid peroxidation; GSH, glutathione; GPx, glutathione peroxidase; RIPA, radioimmunoprecipitation assay; A549, adenocarcinomic human alveolar basal epithelial cells; ZR-75-1, human breast cancer cell line; PC-3, human prostate cancer.

\section{Disclosure}

The authors report no conflicts of interest in this work.

\section{References}

1. Cummings LC, Payes JD, Cooper GS. Survival after hepatic resection in metastatic colorectal cancer: a population-based study. Cancer. 2007;109(4):718-726.

2. Balogh J, Victor D, Asham EH, et al. Hepatocellular carcinoma: a review. J Hepatocell Carcinoma. 2016;3:41-53.

3. Llovet JM, Burroughs A, Bruix J. Hepatocellular carcinoma. Lancet. 2003;362:1907-1917.

4. Benedict M, Zhang X. Non-alcoholic fatty liver disease: An expanded review. World J Hepatol. 2017;9(16): 715“C732.

5. Lafaro KJ, Demirjian AN, Pawlik TM. Epidemiology of hepatocellular carcinoma. Surg Oncol Clin N Am. 2015;24(1):1-17.

6. El-Serag HB, Rudolph KL. Hepatocellular carcinoma: epidemiology and molecular carcinogenesis. Gastroenterology. 2007;132(7):2557-2576

7. Forner A, Llovet JM, Bruix J. Hepatocellular carcinoma. Lancet. 2012;379(9822):1245-1255.

8. Farazi PA, Depinho RA. Hepatocellular carcinoma pathogenesis: from genes to environment. Nat Rev Cancer. 2006;6(9):674-687.

9. Benedict M, Zhang X. Non-alcoholic fatty liver disease: An expanded review. World J Hepatol. 2017;9(16):715-C732

10. El-Serag HB. Epidemiology of viral hepatitis and hepatocellular carcinoma. Gastroenterology. 2012;142(6):1264-1273.

11. Verma A, Ahmed B, Anwar F, et al. Novel glycoside from Wedelia calendulacea inhibits diethyl nitrosamine-induced renal cancer via downregulating the $\mathrm{COX}_{-}$, and $\mathrm{PEG}_{2}$ through nuclear factor- $\mathrm{\kappa B}$ pathway. Inflammopharmacology. 2017;25(1):159-175.

12. Kumar V, Bhatt PC, Rahman M, et al. Fabrication, optimization, and characterization of umbelliferone $\beta$-D-galactopyranoside-loaded PLGA nanoparticles in treatment of hepatocellular carcinoma: in vitro and in vivo studies. Int J Nanomedicine. 2017;12:6747-6758.
13. Kadasa NM, Abdallah H, Afifi M, Gowayed S. Hepatoprotective effects of curcumin against diethyl nitrosamine induced hepatotoxicity in albino rats. Asian Pac J Cancer Prev. 2015;16(1):103-108.

14. Afzal M, Kazmi I, Gupta G, Rahman M, Kimothi V, Anwar F. Preventive effect of Metformin against N-nitrosodiethylamine-initiated hepatocellular carcinoma in rats. Saudi Pharm J. 2012;20(4):365-370.

15. Mandal AK, Ghosh D, Sarkar S, Ghosh A, Swarnakar S, Das N. Nanocapsulated quercetin downregulates rat hepatic MMP-13 and controls diethylnitrosamine-induced carcinoma. Nanomedicine. 2014;9(15): 2323-2337.

16. Calder PC. Polyunsaturated fatty acids and inflammation. Prostaglandins Leukot Essent Fat Acids. 2006;75(3):197-202.

17. Chowdhury R, Warnakula S, Kunutsor S, et al. Association of dietary, circulating, and supplement fatty acids with coronary risk: a systematic review and meta-analysis. Ann Intern Med. 2014;160(6):398-406.

18. Roy S, Rawat AK, Sammi SR, et al. Alpha-linolenic acid stabilizes HIF-1 $\alpha$ and downregulates FASN to promote mitochondrial apoptosis for mammary gland chemoprevention. Oncotarget. 2017;8(41): 70049-70071

19. Saha B, Patro BS, Koli M, Pai G, Ray J, Bandyopadhyay SK, Chattopadhyay S. trans-4,4'-Dihydroxystilbene (DHS) inhibits human neuroblastoma tumor growth and induces mitochondrial and lysosomal damages in neuroblastoma cell lines. Oncotarget. 2017;16;8(43):73905-73924.

20. Yadav RK, Singh M, Roy S, Ansari MN, Saeedan AS, Kaithwas G. Modulation of oxidative stress response by flaxseed oil: Role of lipid peroxidation and underlying mechanisms. Prostaglandins Other Lipid Mediat. 2018;135:21-26.

21. Rani A, Roy S, Singh M, et al. $\alpha$-Chymotrypsin regulates free fatty acids and UCHL-1 to ameliorate N-methyl nitrosourea induced mammary gland carcinoma in albino wistar rats. Inflammopharmacology. 2016; 24(5):277-286.

22. Balakumar P, Taneja G. Fish oil and vascular endothelial protection: bench to bedside. Free Radic Biol Med. 2012;53(2):271-279.

23. Khan R, Kazmi I, Afzal M, et al. Fixed dose combination therapy loperamide and niacin ameliorates diethylnitrosamine-induced liver carcinogenesis in albino Wistar rats. RSC Adv. 2015;5(83):67996-68002.

24. Anwar F, Mushtaq G, Kazmi I, et al. Anticancer effect of rosiglitazone in rats treated with $\mathrm{N}$-nitrosodiethylamine via inhibition of DNA synthesis: an implication for hepatocellular carcinoma. RSC Adv. 2015; 5(84):68385-68391.

25. Kumar V, Bhatt PC, Rahman M, Al-Abbasi FA, Anwar F, Verma A. Umbelliferon- $\alpha$-d-glucopyranosyl-(2 I $\rightarrow 1$ II)- $\alpha$-Dglucopyranoside ameliorates Diethylnitrosamine induced precancerous lesion development in liver via regulation of inflammation, hyperproliferation and antioxidant at pre-clinical stage. Biomed Pharmacother. 2017;94:834-842.

26. Verma A, Singh D, Anwar F, Bhatt PC, Al-Abbasi F, Kumar V. Triterpenoids principle of Wedelia calendulacea attenuated diethynitrosamine-induced hepatocellular carcinoma via downregulating oxidative stress, inflammation and pathology via NF-kB pathway. Inflammopharmacology. 2018;26(1):133-146.

27. Wang Q, Yu WN, Chen X, et al. Spontaneous Hepatocellular Carcinoma after the Combined Deletion of Akt Isoforms. Cancer Cell. 2016; 29(4):523-535.

28. Ghosh D, Choudhury ST, Ghosh S, et al. Nanocapsulated curcumin: oral chemopreventive formulation against diethylnitrosamine induced hepatocellular carcinoma in rat. Chem Biol Interact. 2012;195(3): 206-214.

29. Damodaran A, Kabali B. Autonomic dysfunction in central obesity. World J Med Sci. 2013;8(2):118-122.

30. Henao-Mejia J, Elinav E, Jin C, et al. Inflammasome-mediated dysbiosis regulates progression of NAFLD and obesity. Nature. 2012; 482(7384):179-185.

31. Dapito DH, Mencin A, Gwak GY, et al. Promotion of hepatocellular carcinoma by the intestinal microbiota and TLR4. Cancer Cell. 2012;21(4):504-516. 
32. Iida G, Asano K, Seki M, et al. Intraoperative identification of canine hepatocellular carcinoma with indocyanine green fluorescent imaging. J Small Anim Pract. 2013;54(11):594-600.

33. Sawan AS. Prevalence of Obstruction Meibomian Gland Disease among Ophthalmology Patients. J King Abdulaziz Univ. 2009;16(2):69-76.

34. Park EJ, Lee JH, Yu GY, et al. Dietary and genetic obesity promote liver inflammation and tumorigenesis by enhancing IL-6 and TNF expression. Cell. 2010;140(2):197-208.

35. Lv P, Lin XZ, Li J, Li W, Chen K. Differentiation of small hepatic hemangioma from small hepatocellular carcinoma: recently introduced spectral CT method. Radiology. 2011;259(3):720-729.

36. Abbasi A, Bhutto AR, Butt N, Munir SM. Corelation of serum alpha fetoprotein and tumor size in hepatocellular carcinoma. J Pak Med Assoc. 2012;62(1):33-36.

37. Mizejewski GJ. Levels of alpha-fetoprotein during pregnancy and early infancy in normal and disease states. Obstet Gynecol Surv. 2003; 58(12):804-826.

38. Mizejewski GJ. Biological roles of alpha-fetoprotein during pregnancy and perinatal development. Exp Biol Med. 2004;229(6):439-463.

39. Mizejewski GJ. Review of the putative cell-surface receptors for alpha-fetoprotein: identification of a candidate receptor protein family. Tumour Biol. 2011;32(2):241-258.

40. Hishinuma M, Ohashi KI, Yamauchi N, et al. Hepatocellular oncofetal protein, glypican 3 is a sensitive marker for alpha-fetoprotein-producing gastric carcinoma. Histopathology. 2006;49(5):479-486.

41. Shanab SM, Mostafa SS, Shalaby EA, Mahmoud GI. Aqueous extracts of microalgae exhibit antioxidant and anticancer activities. Asian Pac J Trop Biomed. 2012;2(8):608-615.

42. Luedde T, Beraza N, Kotsikoris V, et al. Deletion of NEMO/IKKgamma in liver parenchymal cells causes steatohepatitis and hepatocellular carcinoma. Cancer Cell. 2007;11(2):119-132.

43. Prasad KN, Xie H, Hao J, et al. Antioxidant and anticancer activities of 8-hydroxypsoralen isolated from wampee [Clausena lansium (Lour.) Skeels] peel. Food Chem. 2010;118(1):62-66.

44. Ip BC, Wang XD. Non-alcoholic steatohepatitis and hepatocellular carcinoma: implications for lycopene intervention. Nutrients. 2013; 6(1):124-162.

45. Sutton A, Nahon P, Pessayre D, et al. Genetic polymorphisms in antioxidant enzymes modulate hepatic iron accumulation and hepatocellular carcinoma development in patients with alcohol-induced cirrhosis. Cancer Res. 2006;66(5):2844-2852.

46. Federico A, Dallio M, Loguercio C. Silymarin/Silybin and chronic liver disease: A marriage of many years. Molecules. 2017;22(2):191.
47. Shimizu M, Shirakami Y, Sakai H, et al. Chemopreventive potential of green tea catechins in hepatocellular carcinoma. Int J Mol Sci. 2015;16(3):6124-6139.

48. Ouyang L, Shi Z, Zhao S, et al. Programmed cell death pathways in cancer: a review of apoptosis, autophagy and programmed necrosis. Cell Prolif. 2012;45(6):487-498.

49. Lunt SY, vander Heiden MG. Aerobic glycolysis: meeting the metabolic requirements of cell proliferation. Annu Rev Cell Dev Biol. 2011;27: $441-464$.

50. Michaylira CZ, Nakagawa H. Hypoxic microenvironment as a cradle for melanoma development and progression. Cancer Biol Ther. 2006; $5(5): 476-479$

51. Pinho SS, Reis CA. Glycosylation in cancer: mechanisms and clinical implications. Nat Rev Cancer. 2015;15(9):540-555.

52. Sarvaiya PJ, Guo D, Ulasov I, Gabikian P, Lesniak MS. Chemokines in tumor progression and metastasis. Oncotarget. 2013;4(12): 2171-2185.

53. Park DH, Shin JW, Park SK, et al. Diethylnitrosamine (DEN) induces irreversible hepatocellular carcinogenesis through overexpression of G1/S-phase regulatory proteins in rat. Toxicol Lett. 2009;191(2-3): 321-326.

54. Guillaumond F, Leca J, Olivares O, et al. Strengthened glycolysis under hypoxia supports tumor symbiosis and hexosamine biosynthesis in pancreatic adenocarcinoma. Proc Natl Acad Sci U S A. 2013; 110(10):3919-3924.

55. Schornack PA, Gillies RJ. Contributions of cell metabolism and $\mathrm{H}+$ diffusion to the acidic pH of tumors. Neoplasia. 2003;5(2):135-145.

56. Wu RSS. Hypoxia: From molecular responses to ecosystem responses. Mar Pollut Bull. 2002;45(1-12):35-45.

57. Aragonés J, Schneider M, van Geyte K, et al. Deficiency or inhibition of oxygen sensor Phd1 induces hypoxia tolerance by reprogramming basal metabolism. Nat Genet. 2008;40(2):170-180.

58. Siddiq A, Ayoub IA, Chavez JC, et al. Hypoxia-inducible factor prolyl 4-hydroxylase inhibition. A target for neuroprotection in the central nervous system. J Biol Chem. 2005;280(50):41732-41743.

59. Woo KJ, Lee TJ, Park JW, Kwon TK. Desferrioxamine, an iron chelator, enhances HIF- $1 \alpha$ accumulation via cyclooxygenase- 2 signaling pathway. Biochem Biophys Res Commun. 2006;343(1):8-14.

60. Bradford MM. A rapid and sensitive method for the quantitation of microgram quantities of protein utilizing the principle of protein-dye binding. Anal Biochem. 1976;72:248-254.
Drug Design, Development and Therapy

\section{Publish your work in this journal}

Drug Design, Development and Therapy is an international, peerreviewed open-access journal that spans the spectrum of drug design and development through to clinical applications. Clinical outcomes, patient safety, and programs for the development and effective, safe, and sustained use of medicines are the features of the journal, which

\section{Dovepress}

has also been accepted for indexing on PubMed Central. The manuscript management system is completely online and includes a very quick and fair peer-review system, which is all easy to use. Visit http://www.dovepress.com/testimonials.php to read real quotes from published authors. 